Bond University

Research Repository

\author{
Altered ureteral contractility with ageing \\ Role of the rho-kinase pathway \\ Lim, Iris; Chess-Williams, Russ; Sellers, Donna \\ Published in: \\ Mechanisms of Ageing and Development
}

DOI:

10.1016/j.mad.2018.03.004

Licence:

CC BY-NC-ND

Link to output in Bond University research repository.

Recommended citation(APA):

Lim, I., Chess-Williams, R., \& Sellers, D. (2018). Altered ureteral contractility with ageing: Role of the rho-kinase pathway. Mechanisms of Ageing and Development, 171, 31-36. https://doi.org/10.1016/j.mad.2018.03.004

\footnotetext{
General rights

Copyright and moral rights for the publications made accessible in the public portal are retained by the authors and/or other copyright owners and it is a condition of accessing publications that users recognise and abide by the legal requirements associated with these rights.
}

For more information, or if you believe that this document breaches copyright, please contact the Bond University research repository coordinator. 


\section{Altered ureteral contractility with ageing: role of the rho-kinase pathway}

Iris Lim, Russ Chess-Williams, and Donna Sellers

Centre for Urology Research, Faculty of Health Science \& Medicine, Bond University, QLD 4229, Australia

\section{Corresponding Author:}

Iris Lim, Centre for Urology Research, Faculty of Health Science \& Medicine, Bond University, QLD 4229, Australia Email: ilim@bond.edu.au Tel: +617 55955546 


\section{Introduction}

The incidence of urolithiasis, the formation of kidney stones, is high in western countries, affecting 1 in 10 individuals (Macneil \& Bariol, 2011) and its prevalence is expected to escalate significantly in the coming decades (Soucie, et al., 1994; Lee, et al., 2002). While the pathophysiology of urolithiasis has not been clearly elucidated, this condition is frequently accompanied with ureteral colic, which is understood to be caused by constriction of the ureteric tube. The most common location for lodgement of kidney stones is the distal ureter approaching the ureterovesical junction where the ureter enters the bladder (El-Barky, et al., 2014). Although normal ureteral contractility is dependent on peristaltic waves originating from pacemaker cells, it also relies on effective contraction and relaxation of the smooth muscle cells which constitute the bulk of the ureteral wall (Lang \& Klemm, 2005). While it is well established that calcium is the intracellular trigger for smooth muscle contraction, recent research has demonstrated that smooth muscle contraction can occur even in the absence of large changes in calcium, a process currently defined as 'calcium sensitization' (Zhang \& DiSanto, 2011; de Godoy \& Rattan, 2011). A major enzyme involved in this pathway is rhokinase, which is activated via G-protein coupled receptors by the monomeric GTP-binding protein RhoA (Christ \& Andersson, 2007).

A limited number of studies have focused on the importance of rho-kinase in the ureter. In the rat ureter, it has been shown that rho-kinase inhibitors (Y-27632, fasudil and $\mathrm{H}-1152$ ) significantly decrease phasic contractions (Shabir, et al., 2004). This indicates that rho-kinase inhibition can modulate phasic contractions in the absence of calcium changes, suggesting a role for rho-kinase in calcium sensitization in ureteral smooth muscle. However, this was not evident in the guinea-pig ureter, indicating there are species differences (Shabir, et al., 2004). In addition, another study on the sheep ureter demonstrated the presence of both isoforms of rho-kinase (rho-kinase-I and rho-kinase-II) and its mediation of agonist and electrical field stimulated (EFS) contractions, as well as spontaneous contractile activity (Levent \& Buyukafsar, 2004). Immunohistochemistry and immunoblotting studies have demonstrated the presence of both rho-kinase isoforms in the human ureter, where spontaneous and EFSinduced contractile responses were depressed by the rho-kinase inhibitor Y-27632 (Hong, et al., 2005).

It has been proposed that rho-kinase-mediated contractile mechanisms could be extensively altered in response to pathological insults and with ageing. Unilateral ureteral obstruction, as seen with ureteral stones, has been shown to enhance expression of rho-kinase-I and rhokinase-II in the rabbit ureter and contractility was also enhanced in ureteral strips from rabbits with ureteral obstruction (Turna, et al., 2007). Furthermore, rho-kinase inhibition with Y-27632 
significantly suppressed contractility in both unilaterally obstructed and control ureters and reduced contractions in the obstructed ureters back to control levels (Turna, et al., 2007).

Whilst no studies have investigated the effect of age on the rho-kinase pathway in the ureter, the calcium sensitization pathway has been shown to be altered with age in some tissues within the urinary tract. In the guinea pig bladder, contractions of detrusor smooth muscle strips were sensitive to blockade with Y-27632, although this inhibitor had a negligible effect on tissue strips from older animals, suggesting the possibility of alterations in rho-kinase expression and/or activity with age (Gomez-Pinilla, et al., 2008). Furthermore, in the human bladder, there was a strong correlation between the amount of inhibition of contractility by $\mathrm{Y}$ 27632 with age, suggesting that rho-kinase-mediated contractions are age-dependent (Kirschstein, et al., 2014).

The aim of this study was to investigate the effects of the rho-kinase inhibitors, Y-27632 and fasudil, on contractility of isolated distal ureter from young and older pigs, a species with similar urinary tract pharmacology and physiology to human. 


\section{Methods and Materials}

\subsection{Tissue Preparation}

Fresh bladders, with ureters attached, from 6-month old (young) and 3-year old (older) female pigs were obtained from a local abattoir and immediately immersed in ice-cold Krebsbicarbonate solution $\left(4^{\circ} \mathrm{C}\right)$ composed of $\mathrm{NaCl}(188.4 \mathrm{mM}), \mathrm{NaHCO}_{3}(24.9 \mathrm{mM})$, glucose $(11.7$ $\mathrm{mM}), \mathrm{CaCl}_{2}(1.9 \mathrm{mM}), \mathrm{MgSO}_{4}(1.2 \mathrm{mM})$ and $\mathrm{KH}_{2} \mathrm{PO}_{4}(1.2 \mathrm{mM})$. The ureters were detached from the bladders and the peri-ureteric fat was removed. The distal ureter was determined as being the region $5 \mathrm{~cm}$ from the entrance to the bladder, and this section was used to dissect $4 \mathrm{~mm}$ long tissue strips.

Tissue strips were mounted longitudinally under $1 \mathrm{~g}$ tension in $8 \mathrm{ml}$ organ baths (EZ-baths, Global Towns, CA) containing Krebs-bicarbonate solution, maintained at $37^{\circ} \mathrm{C}$ and continuously gassed with $95 \% \mathrm{O}_{2}$ and $5 \% \mathrm{CO}_{2}$. Isometric tension developed by the tissues was recorded via a Powerlab recording system and Labchart software (ADInstruments, Castle Hill, Australia).

\subsection{The effect of rho-kinase inhibition on contractility of ureters}

Ureteral tissue strips were isolated and cut in half: one strip acting as a control while the other was incubated for 30 minutes with one of the rho-kinase inhibitors, Y-27632 (10 $\mu \mathrm{M})$ or fasudil $(30 \mu \mathrm{M})$, before addition of an $\mathrm{EC}_{50}$ concentration (termed "low dose") of the $\alpha 1$-adrenoceptor agonist phenylephrine $(30 \mu \mathrm{M})$ or $5-\mathrm{HT}(10 \mu \mathrm{M})$. The responses to the agonists were recorded, and then after washout and return to baseline, a maximally effective concentration (termed "high dose") of the same agonist (phenylephrine $300 \mu \mathrm{M}$ or 5-HT $100 \mu \mathrm{M}$ ) was added. The rho-kinase inhibitor was present throughout the experiment. The agonist concentrations were determined based on preliminary concentration-response curves (Figure 1). Each ureteral tissue strip was exposed to only one inhibitor and one agonist. The contractile responses were measured as area under the curve ( $\mathrm{g} \mathrm{s}$ ) and frequency $(\mathrm{Hz})$.

\subsection{Measurement of rho-kinase activity in ureteral smooth muscle}

A rho-kinase activity assay (Cell BioLabs, Inc) was performed as per manufacturer's instructions on isolated distal ureteral tissue strips freshly homogenised with a RIPA lysis buffer system (Santa Cruz Biotechnology, Inc). This enzyme immunoassay detects the specific phosphorylation of MYPT1 at $\mathrm{Thr}^{696}$ by rho-kinase. The assays were performed in duplicate on tissue lysates of isolated ureteral strips incubated in the absence and presence of low and high concentrations of phenylephrine and 5-HT, as used in the functional contraction experiments, and in ureters from both age groups. 


\subsection{Materials}

All components of Krebs bicarbonate solution were purchased from Sigma-Aldrich, New South Wales, Australia. The following drugs were used: 5-hydroxytryptamine hydrochloride (Abcam, Cambridge, U.S.A.), (R)-(-)-phenylephrine hydrochloride (Sigma-Aldrich, New South Wales, Australia), Y-27632 dihydrochloride (Tocris, Victoria, Australia) and fasudil hydrochloride (Tocris, Victoria, Australia). All drugs were dissolved in distilled water and dilutions performed using Krebs bicarbonate solution.

\subsection{Data analysis}

Paired Student's $t$-tests were used to compare data from two groups, while two-way ANOVA followed by Dunnett's post hoc test was used to compare data from more than two groups. 


\section{Results}

Porcine ureteral strips were allowed to equilibrate to a passive tension of $1.19 \pm 0.06 \mathrm{~g}(\mathrm{n}=96)$. Spontaneous contractions developed during the equilibration period in 16 of 96 ureteral strips (11.7\%). When subjected to the agonists phenylephrine and 5-HT, all ureteral strips, from both age groups, demonstrated triggered bursts of phasic contractions, the frequency of which was concentration-dependent, with greater rates of phasic contractions at the higher concentrations of agonist (Figure 1).

\subsection{Effect of age on phenylephrine and 5-HT-induced contractility of ureters}

The potency ( $\mathrm{pEC} 50$ ) of both agonists in producing contraction of ureteral strips was similar for tissues from both age groups (young vs older: $4.42 \pm 0.18$ vs $4.83 \pm 1.43$ for phenylephrine, $5.16 \pm 0.09$ vs $5.43 \pm 0.16$ for $5-\mathrm{HT}$ ). However, the maximum contractile responses expressed as AUC, to phenylephrine were significantly enhanced in ureteral strips from the older animals (Figure 1A, unpaired $t$-test, $\mathrm{p}<0.001$ ). Phenylephrine-induced frequency of contractions was also greater in ureteral strips from older animals (Figure $1 C$, unpaired $t$-test, $p<0.05$ ). In contrast, 5-HT maximum contractile responses (AUC) were depressed in tissues from older animals (Figure $1 \mathrm{~B}$, unpaired $t$-test, $p<0.001$ ), whilst the maximum frequency response to 5 HT was similar in tissue strips from both age groups (Figure 1D).

(A)

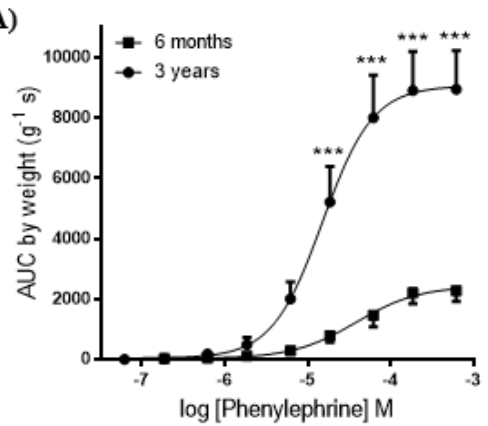

(C)

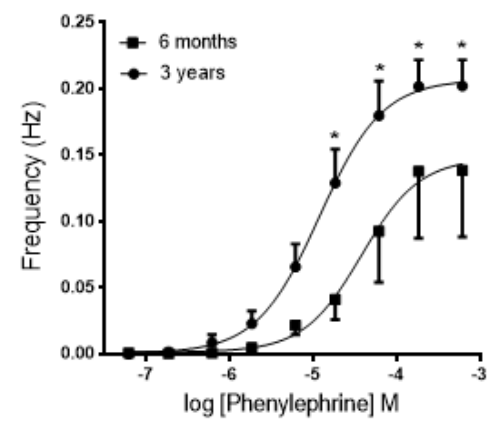

(B)

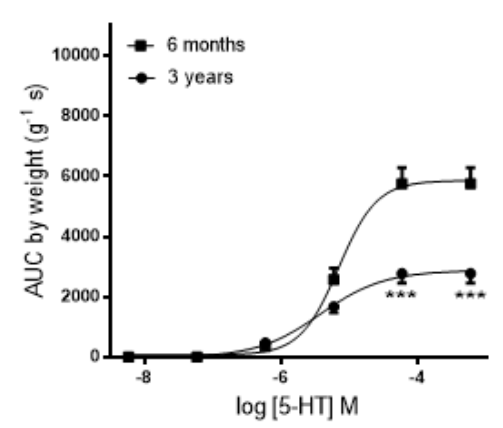

(D)

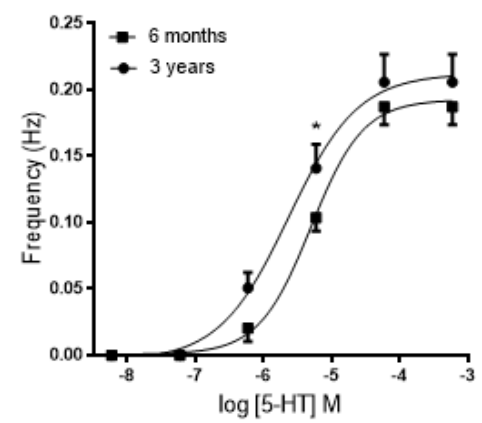

Figure 1. Contractility of ureteral strips. Mean ( \pm SEM) concentration-response curves for phenylephrine $(A, C)$ and $5-H T(B, D)$ in ureteral tissues from young (6 months) and older (3 years) pigs. Responses are expressed as $A \cup C$ by weight in grams per second $(A, B)$ and frequency in $\mathrm{Hz}(C, D)(n$ $=8,{ }^{*} p<0.05,{ }^{* *} p<0.005,{ }^{* \star *} p<0.0005$ vs young). 
3.2 Effect of the rho kinase inhibitor Y-27632 on phenylephrine-induced contractile responses Incubation of ureteral strips with the rho-kinase inhibitor $\mathrm{Y}-27632(10 \mu \mathrm{M})$ significantly depressed phenylephrine-induced contractions in tissues from both young and older animals, when responses were expressed as AUC (Figures $2 \mathrm{~A}$ and $2 \mathrm{C}$, paired $t$-test, $\mathrm{p}<0.005$ ). $\mathrm{Y}$ 27632 produced a greater inhibition of contractions induced by the high dose of phenylephrine in tissues from older animals compared to those from young animals (Table 1, unpaired $t$-test, $p<0.05$ ), but this was not observed when tissues were stimulated with the low dose of phenylephrine.

In ureteral strips from both age-groups, the frequency of contractions induced by the high dose phenylephrine was significantly inhibited by $\mathrm{Y}-27632$, but not those induced by low dose of phenylephrine (Figures $2 \mathrm{~A}$ and $2 \mathrm{C}$, paired $t$-test, $\mathrm{p}<0.005$ ). Similar to $\mathrm{AUC}$ data, the frequency of phenylephrine-induced contractions was also inhibited by $\mathrm{Y}-27632$ to a greater extent in tissues from older animals, at the high dose phenylephrine (Table 1, unpaired $t$-test, $p<0.05$ ).

6 months (young)

(A) Phenylephrine
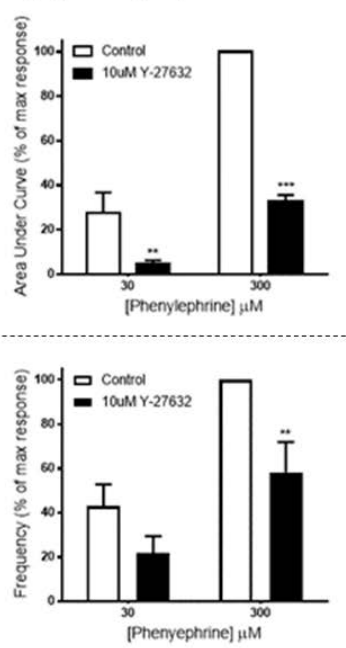

(B) 5-HT
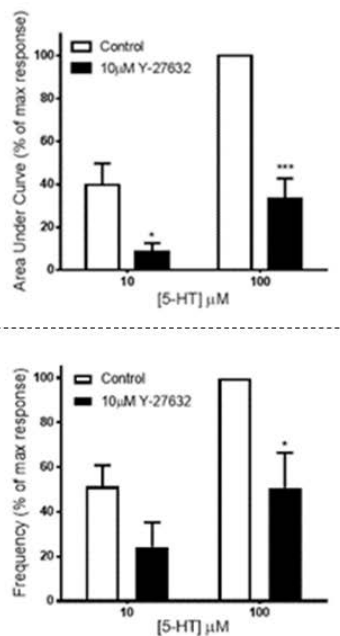

3 years (older)

(C) Phenylephrine

(D) 5 -HT
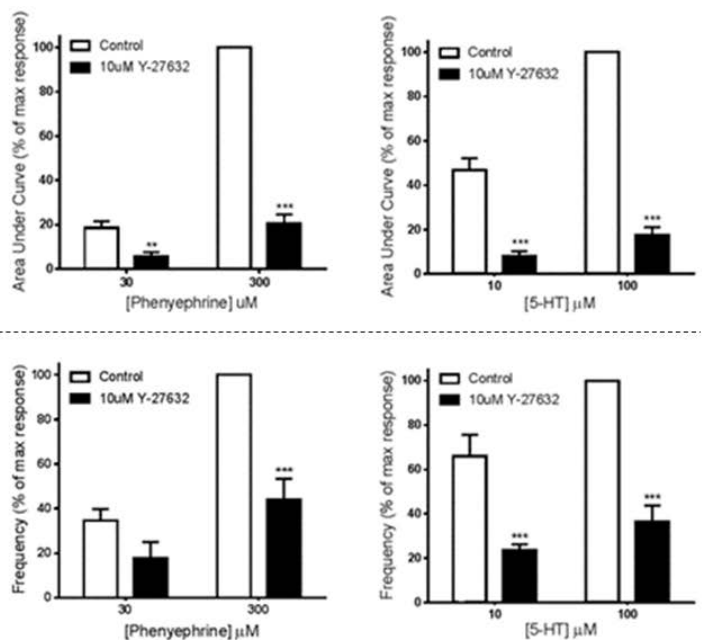

Figure 2. The effect of $\underline{Y-27632}\left(\begin{array}{ll}10 & \mu M\end{array}\right)$ on contractile responses to low and high doses of phenylephrine $(A, C)$ and $5-H T(B, D)$ in porcine ureteral strips from young $(A, B)$ and older $(C, D)$ animals. Responses are represented as mean \pm SEM percentage of maximal response in AUC and frequency $\left(n=6,{ }^{*} p<0.05,{ }^{*} p<0.005, p^{*}<0.001\right.$ vs control).

\subsection{Effect of the rho-kinase inhibitor Y-27632 on 5-HT-induced contractile responses}

$\mathrm{Y}-27632(10 \mu \mathrm{M})$ inhibited contractions induced by both low and high doses of 5-HT, when expressed as AUC, in tissues from young and older animals (Figures $2 \mathrm{~B}$ and $2 \mathrm{D}$, paired $t$-test, $\mathrm{p}<0.05)$. Y-27632 had a greater inhibitory effect on 5-HT-induced responses in ureteral strips from older animals at the high dose of $5-\mathrm{HT}$, in comparison to tissues from younger animals (Table 1, unpaired $t$-test, $\mathrm{p}<0.05$ ). 
The frequency of contractile responses to both low and high doses of 5-HT was also significantly inhibited by $\mathrm{Y}$-27632 in tissues from older animals (Figure 2D, paired $t$-test, $p<0.001$ ), although in tissues from the younger animals, the inhibition was only statistically significant at the high dose of 5-HT (Figure 2B, paired $t$-test, $\mathrm{p}<0.05$ ). The inhibition of 5 -HTstimulated contractions by $\mathrm{Y}-27632$ was greater in tissues from older animals compared to those from the young group (Table 1 , unpaired $t$-test, $p<0.05$ ).

Table 1. Inhibition of contractile responses by rho-kinase inhibitors. Mean ( \pm SEM) inhibition by Y-27632 and fasudil of responses to phenylephrine and 5-HT in ureter from young and older animals. $\left({ }^{*} p<0.05\right.$ vs corresponding values in tissues from young pigs)

\begin{tabular}{|c|c|c|c|c|c|}
\hline \multirow{2}{*}{ Agonist } & \multirow{2}{*}{ Inhibitor } & \multicolumn{2}{|c|}{6 months (young) } & \multicolumn{2}{|c|}{3 years (older) } \\
\hline & & AUC & Frequency & AUC & Frequency \\
\hline \multirow{2}{*}{$\begin{array}{l}\text { Phenylephrine } \\
(30 \mu \mathrm{M})\end{array}$} & $\begin{array}{l}\mathrm{Y}-27632 \\
(10 \mu \mathrm{M})\end{array}$ & $82.0 \pm 9.4 \%$ & $49.9 \pm 9.8 \%$ & $69.9 \pm 4.8 \%$ & $51.4 \pm 8.2 \%$ \\
\hline & $\begin{array}{l}\text { Fasudil } \\
(30 \mu \mathrm{M})\end{array}$ & $89.8 \pm 9.2 \%$ & $58.0 \pm 5.2 \%$ & $84.0 \pm 3.9 \%$ & $48.0 \pm 4.2 \%$ \\
\hline \multirow{2}{*}{$\begin{array}{l}\text { Phenylephrine } \\
(300 \mu \mathrm{M})\end{array}$} & $\begin{array}{l}\mathrm{Y}-27632 \\
(10 \mu \mathrm{M})\end{array}$ & $67.4 \pm 3.0 \%$ & $41.7 \pm 5.7 \%$ & $79.5 \pm 4.1 \%$ * & $56.0 \pm 4.1 \% *$ \\
\hline & $\begin{array}{l}\text { Fasudil } \\
(30 \mu \mathrm{M})\end{array}$ & $81.9 \pm 3.0 \%$ & $40.9 \pm 5.2 \%$ & $78.7 \pm 3.0 \%$ & $30.0 \pm 5.6 \%$ \\
\hline \multirow{2}{*}{ 5-HT $(10 \mu \mathrm{M})$} & $\begin{array}{l}\mathrm{Y}-27632 \\
(10 \mu \mathrm{M})\end{array}$ & $78.5 \pm 9.9 \%$ & $48.2 \pm 9.5 \%$ & $82.6 \pm 7.5 \%$ & $64.1 \pm 6.2 \% *$ \\
\hline & $\begin{array}{l}\text { Fasudil } \\
(30 \mu \mathrm{M})\end{array}$ & $83.7 \pm 6.2 \%$ & $62.8 \pm 3.7 \%$ & $80.1 \pm 6.9 \%$ & $54.2 \pm 3.2 \%$ \\
\hline \multirow{2}{*}{ 5-HT (100 нM) } & $\begin{array}{l}\mathrm{Y}-27632 \\
(10 \mu \mathrm{M})\end{array}$ & $66.6 \pm 5.4 \%$ & $49.2 \pm 5.3 \%$ & $81.6 \pm 3.7 \% *$ & $63.4 \pm 5.6 \%$ * \\
\hline & $\begin{array}{l}\text { Fasudil } \\
(30 \mu \mathrm{M})\end{array}$ & $77.7 \pm 3.2 \%$ & $45.6 \pm 3.7 \%$ & $79.3 \pm 3.2 \%$ & $65.5 \pm 4.5 \%$ * \\
\hline
\end{tabular}

\subsection{Effect of the rho-kinase inhibitor fasudil on phenylephrine-induced ureteral responses} Incubation of ureteral strips from young and older animals with fasudil (30 $\mu \mathrm{M})$ significantly reduced contractions (AUC) and frequency, induced by high and low doses of phenylephrine (Figures $3 A$ and $3 C$, paired $t$-test, $\mathrm{p}<0.05$ ). This inhibition was similar in tissues from both age groups (Table 1). 


\subsection{Effect of the rho-kinase inhibitor fasudil on 5-HT-induced ureteral responses}

Similar to Y-27632, fasudil also suppressed contractile activity induced by low and high doses of 5-HT, when expressed as AUC and frequency, in ureteral strips from both young and older animals (Figures 3B and 3D, paired $t$-test, $\mathrm{p}<0.001$ ). Fasudil inhibited 5 -HT-induced responses expressed as AUC in a similar manner in tissues from both age groups (Table 1). However, frequency of contractions induced by high dose of 5-HT, but not the low dose, was inhibited by fasudil to a greater extent in tissues from older animals in comparison to those from young animals (Table 1, unpaired $t$-test, $p<0.05$ ).

6 months (young)

(A) Phenylephrine
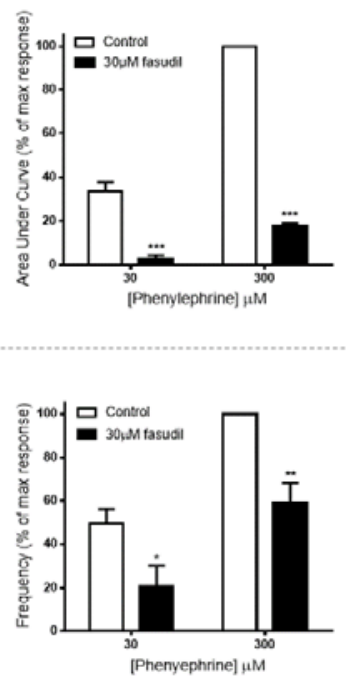

(B) 5-HT
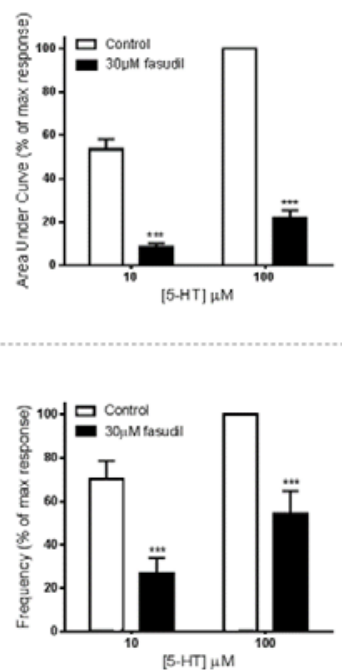

3 years (older)

(C) Phenylephrine

(D) 5-HT
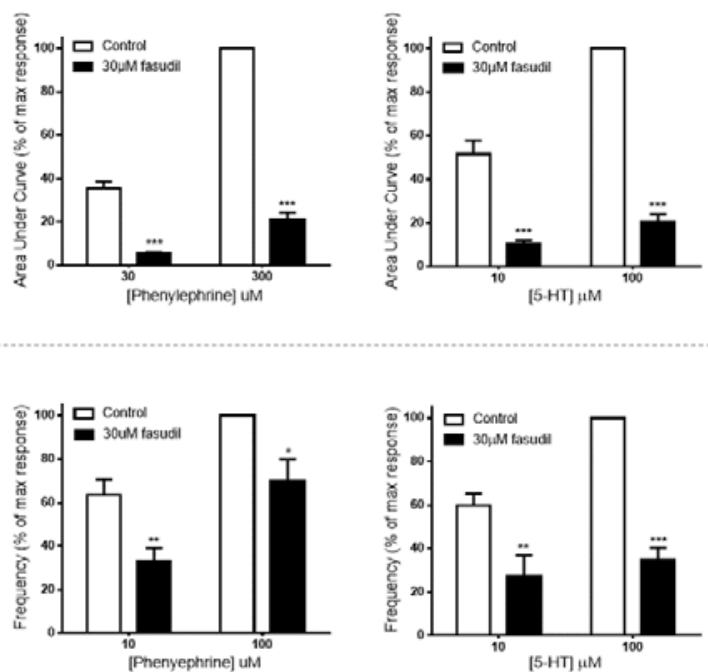

Figure 3. The effect of fasudil ( $\mathbf{3 0} \mu \mathrm{M})$ on contractile responses to low and high doses of phenylephrine $(A, C)$ and 5-HT $(B, D)$ in porcine ureteral strips from young $(A, B)$ and older $(C, D)$ animals. Responses are represented as mean $\pm S E M$ percentage of maximal response in $A U C$ and frequency $\left(n=6,{ }^{*} p<0.05\right.$, ${ }^{*} p<0.005, p^{*}<0.001$ vs control).

\subsection{Rho-kinase activity in ureteral tissues}

Using a commercially available assay, active rho-kinase levels were determined in tissue lysates of ureters from young and older animals. As seen in Figure 4, basal levels of active rho-kinase were found to be similar in ureters from young and older animals and were not elevated following stimulation with either phenylephrine or 5-HT. However, greater rho-kinase activity was observed only in ureters from the older animals compared to young when stimulated with a low dose of phenylephrine (Figure 4, two-way ANOVA, $p<0.05$ ). Additionally, rho-kinase activity was significantly depressed in ureter from older animals following stimulation with high dose 5-HT (Figure 4, two-way ANOVA, p<0.05). 


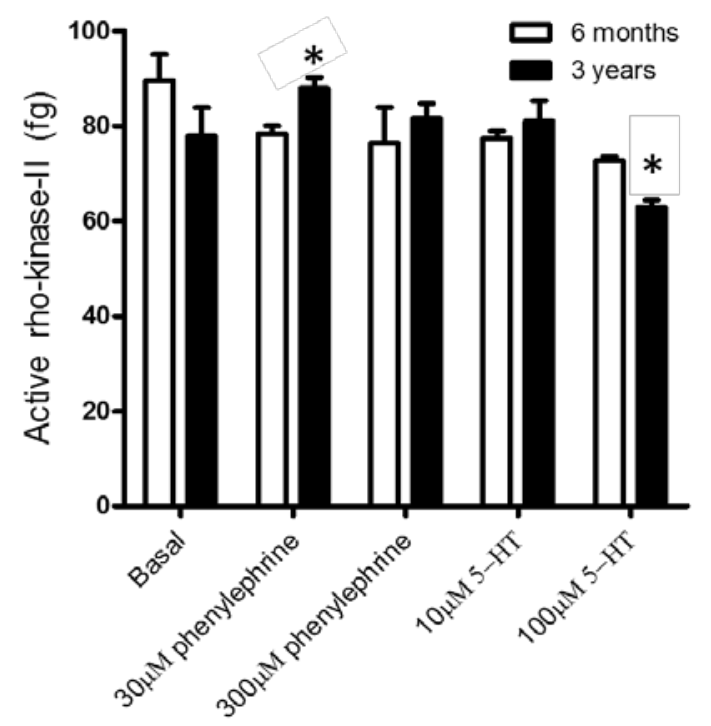

Figure 4. Rho-kinase activity in isolated porcine ureteral smooth muscle from young (6 months) and older (3 years) pigs. Mean ( \pm SEM) values from 3 experiments each performed in duplicate $\left({ }^{*} p<0.05 \mathrm{vs}\right.$ tissues from younger animals). 


\section{Discussion}

The present study sought to investigate the importance of the rho-kinase pathway in agonistinduced contractility of the ureter. The main findings demonstrate that the rho-kinase pathway is vital in contractile responses to phenylephrine and $5-\mathrm{HT}$ of the porcine distal ureter. This confirms previous reports suggesting a role for the calcium sensitization pathway in ureteral contraction, and demonstrates that the pig is similar to other species including sheep, rat, and guinea-pig (Levent \& Buyukafsar, 2004; Shabir, et al., 2004; Borysova, et al., 2011) .

According to our functional studies, we confirm that both of the rho-kinase inhibitors Y-27632 and fasudil were able to suppress phenylephrine- and 5-HT-induced contractions of the porcine distal ureter. In our preliminary data (unpublished), the contractile responses in the porcine distal ureter to stimulation of muscarinic receptors were much smaller in comparison to those recorded in response to $\alpha_{1}$-adrenoceptor and 5-HT receptor stimulation. The involvement of $\alpha_{1}$-adrenoceptor stimulation in contractile responses of the ureter has been well established (Hernandez, et al., 1992; Sasaki, et al., 2011). 5-HT receptors have also recently been shown to play a vital role, where stimulation of $5-\mathrm{HT}$ receptors resulted in concentration-dependent contractions of the porcine ureter (Lim, et al., 2017). The source of endogenous 5-HT in the ureter is still unclear. Since 5-HT-containing enterochromaffin cells could not be found in the ureter, it appears that platelets and mast cells might be the source of 5-HT in this tissue (Ripoche, 2011). The role for mast cells in the inflammatory process has been observed in all layers of the porcine ureteral wall and are likely to be involved in the regulation of ureteral motility via the release of mediators including $5-\mathrm{HT}$ in inflammatory circumstances (Vodenicharov, et al., 2005) Consistent with our results in the pig ureter, the role of the rho-kinase pathway following activation of this receptor has also been characterised in sheep ureter (Levent \& Buyukafsar, 2004). Based on our current knowledge of the literature, we are the first to demonstrate a role for rho-kinase in 5-HT-stimulated contractile responses of the ureter.

In order to investigate whether the role of rho-kinase changes with ageing, the effect of two rho-kinase inhibitors was compared in ureters from two different aged animals (6 months and 3 years). Y-27632, but not fasudil, appears to have a greater inhibitory effect on ureteral contractility in tissues from older animals compared to those from the young animals. This greater inhibitory effect was seen at both concentrations of $5-\mathrm{HT}$, and at the high concentration of phenylephrine, although not at the low dose of phenylephrine. The reason for the different result at the low concentration of phenylephrine is not known, but generally the effects of $Y$ 27632 were greater in the tissues from older animals. This is supported in the literature by Gao et al., (2007), who observed similar age-related differences in effectiveness of Y-27632, 
with an improvement of erectile dysfunction in rats that was significantly greater in older animals. It has been reported that $\mathrm{Y}-27632$ has a greater selectivity for rho-kinase than fasudil, and so it is possible that fasudil might have effects on other kinases affecting smooth muscle contractility in the ureter (Rattan \& Patel, 2008).

Our findings show that there was an overall dissimilarity between basal rho-kinase activity and agonist-induced activity in tissue lysate of distal ureter from both age groups. This suggests that activation of $\alpha_{1}$-adrenoceptor and 5-HT receptors did not increase rho-kinase activity in the tissues but there was a basal level of activity which potentiates responses to agonists. Upon addition of rho-kinase inhibitors to tissue strips in our functional studies, there was no decrease in baseline tone, but this does not necessarily indicate that there was no rho-kinase activity present at basal levels, since baseline was set to a very low tension (approximately 1 g). Whilst we did not have sufficient number of tissue strips for each group (control and inhibitor) that developed spontaneous contractions to statistically determine whether the rho-kinase inhibitors had inhibitory effects on basal frequency responses, several studies have shown that rho-kinase inhibitors are capable of inhibiting spontaneous contractions of the ureter in various species including rat (Shabir, et al., 2004), sheep (Levent \& Buyukafsar, 2004), and human (Hong, et al., 2005). These findings support our hypothesis that a basal level of rhokinase activity is present without stimulation from agonists.

In tissue lysates from older animals, we found that rho-kinase activity was significantly greater following low dose of phenylephrine in comparison to tissues from younger pigs. The opposite was observed with the high dose of $5-\mathrm{HT}$, where ureteral lysates from older animals had depressed rho-kinase activity. While we are careful not to draw conclusions, since these alterations were only observed at one concentration of agonist and not the other, these findings suggest that alterations of rho-kinase activity occur with ageing. Interestingly, when subjected to cumulative concentrations of phenylephrine, there is an increase in maximum contractile responses in tissues from older animals and greater 5-HT-induced contractions in younger animals. In addition to this, it has been shown in that mediation of carbachol-induced contractions in the human detrusor via the rho-kinase pathway is positively correlated with age (Kirschstein, et al., 2014). Therefore, it is suggested that age-related agonist-induced contractions are associated to alterations in rho-kinase activity. 


\section{Conclusions}

Our study shows that the rho-kinase pathway plays a major role in normal ureteral function, and that rho-kinase inhibitors appear to have altered effectiveness with ageing. While it will be beneficial to clarify the potential of utilising rho-kinase inhibitors therapeutically in vivo and in the clinical setting, we believe that the rho-kinase pathway could be an interesting target for drugs aimed at increasing kidney stone expulsion by relieving ureteral pressure. 


\section{References}

Borysova, L., Shabir, S., Walsh, M. P. \& Burdyga, T., 2011. The importance of Rhoassociated kinase-induced $\mathrm{Ca} 2+$ sensitization as a component of electromechanical and pharmacomechanical coupling in rat ureteric smooth muscle.. Cell Calcium, 50(4), pp. 393405.

Christ, G. J. \& Andersson, K. E., 2007. Rho-kinase and effects of Rho-kinase inhibition on the lower urinary tract.. Neurourol Urodyn, 26(6 Suppl), pp. 948-954.

de Godoy, M. A. \& Rattan, S., 2011. Role of rho kinase in the functional and dysfunctional tonic smooth muscles.. Trends Pharmacol Sci, 32(7), pp. 384-393.

El-Barky, E. et al., 2014. Site of impaction of ureteric calculi requiring surgical intervention.. Urolithiasis , 42(1), pp. 67-73.

Gao, B. et al., 2007. Y-27632 improves the erectile dysfunction with ageing in SD rats through adjusting the imbalance between $\mathrm{nNo}$ and the Rho-kinase pathways.. Andrologia, 39(4), pp. 146-150.

Gomez-Pinilla, P. J. et al., 2008. Melatonin restores impaired contractility in aged guinea pig urinary bladder.. J Pineal Res, 44(4), pp. 416-425.

Heilbrunn, L. V. \& Wiercinski, F. J., 1947. The action of various cations on muscle protoplasm. J Cell Comp Physiol, 29(1), pp. 15-32.

Hernandez, M. et al., 1992. Noradrenaline modulates smooth muscle activity of the isolated intravesical ureter of the pig through different types of adrenoceptors.. Br J Pharmacol, 107(4), pp. 924-931.

Hong, S. K. et al., 2005. Involvement of Rho-kinase in the contractile mechanism of human ureteral smooth muscle.. Neurourol Urodyn, 24(2), pp. 136-141.

Kirschstein, T. et al., 2014. Age-dependent contribution of Rho kinase in carbachol-induced contraction of human detrusor smooth muscle in vitro.. Acta Pharmacol Sin., 35(1), pp. 7481.

Lang, R. J. \& Klemm, M. F., 2005. Interstitial cell of Cajal-like cells in the upper urinary tract. J Cell Mol Med, 9(3), pp. 543-556.

Lee, Y. H. et al., 2002. Epidemiological studies on the prevalence of upper urinary calculi in Taiwan.. Urol Int, 68(3), pp. 172-177.

Levent, A. \& Buyukafsar, K., 2004. Expression of Rho-kinase (ROCK-1 and ROCK-2) and its substantial role in the contractile activity of the sheep ureter.. Br J Pharmacol, 143(3), pp.

431-437.

Lim, I., Chess-Williams, R. \& Sellers, D., 2017. 5-HT2A receptor is the predominant receptor mediating contraction of the isolated porcine distal ureter to $5-\mathrm{HT}$ in young and old animals.. Eur J Pharmacol, Volume 818, pp. 328-334.

Macneil, F. \& Bariol, S., 2011. Urinary stone disease - assessment and management.. Australian Family Physician, 40(10), pp. 772-775.

Rattan, S. \& Patel, C., 2008. Selectivity of ROCK inhibitors in the spontaneously tonic smooth muscle. Am J Physiol Gastrointest Liver Physiol, 294(3), pp. G687-G693.

Ripoche, J., 2011. Blood platelets and inflammation: their relationship with liver and digestive diseases.. Clin Res Hepatol Gastroenterol, 35(5), pp. 353-357.

Sasaki, S. et al., 2011. Characterization of a1-adrenoceptor subtypes mediating contraction in human isolated ureters.. Urology, 77(3), p. 762.

Shabir, S., Borisova, L., Wray, S. \& Burdyga, T., 2004. Rho-kinase inhibition and electromechanical coupling in rat and guinea-pig ureter smooth muscle: Ca2+-dependent and -independent mechanisms.. J Physiol, 560(Pt 3), pp. 839-855.

Soucie, J. M. et al., 1994. Demographic and geographic variability of kidney stones in the United States.. Kidney Int, Sep, 46(3), pp. 893-899.

Turna, B. et al., 2007. Role of Rho-kinase in contractions of ureters from rabbits with unilateral ureteric obstruction.. BJU Int, 100(5), pp. 1166-1171.

Vodenicharov, A., Leiser, R., Gulubova, M. \& Vlaykova, T., 2005. Morphological and immunocytochemical investigations on mast cells in porcine ureter.. Anat Histol Embryol, 34(6), pp. 343-349. 
Zhang, X. \& DiSanto, M. E., 2011. Rho-kinase, a common final path of various contractile bladder and ureter stimuli.. Handb Exp Pharmacol, (202), pp. 543-568. 